\title{
Problematização de Temáticas de Promoção da Saúde do Idoso a partir de uma Vivência Dramatúrgica
}

\section{Problematization about Elderly Health Promotion Themes based on a Dramatistic Experience}

Antônio Carlos Gomes do Espírito Santo

Doutor em Saúde Pública pela USP, Professor Adjunto do Departamento de Medicina Social da Universidade Federal de Pernambuco (UFPE).

Endereço: Rua Costa Gomes, 180 apto 1103 , Madalena, CEP 50710510, Recife, PE, Brasil.

E-mail: ag.santoळyahoo.com.br

\section{Ana Paula de Oliveira Marques}

Doutora em Nutrição pela UFPE, Professora Adjunta do Departamento de Medicina Social da UFPE, Coordenadora do Proidoso/UFPE. Endereço: Rua João Eugênio de Lima, 67 apto 402, Boa Viagem, CEP 51030-360, Recife, PE, Brasil.

E-mail: marquesapœhotmail.com

\section{Márcia Carrera Campos Leal}

Doutora em Odontologia Preventiva pela UPE, Professora Adjunta do Departamento de Medicina Social da UFPE, Coordenadora do Núcleo de Atenção ao Idoso da UFPE.

Endereço: Rua Dr. João Santos Filho, 250 apto 1901, Casa Forte, CEP 52060-615, Recife, PE, Brasil.

E-mail: mcarreraळibest.com

\section{Sophia Karlla Almeida Mota}

Mestre em Lingüística pela UFPE, Pesquisadora do Núcleo de Saúde Pública e Desenvolvimento Social da UFPE.

Endereço: Rua João Julião, 296 apto 43-A, Paraíso, CEP 01323-020, São Paulo, SP, Brasil.

E-mail: sophiaळcidadessaudaveis.org.br

Mário Roberto Agostinho da Silva

Psicólogo, membro da Equipe Técnica do Núcleo de Atenção ao Idoso da UFPE.

Endereço: Rua Helena Vilarim Feitosa, 58, Jardim Santa Rita, CEP

53250-180, Olinda, PE, Brasil.

\section{Resumo}

Este artigo apresenta o relato de uma experiência de ensino-aprendizagem tendo como temática a promoção da saúde do idoso no contexto familiar, utilizando uma abordagem pedagógico-construtivista, seguindose uma linha problematizadora, optando-se por uma estratégia pautada na construção coletiva de um texto dramatúrgico, na sua encenação e discussão. Participaram da experiência docentes pesquisadores, técnicos e alunos de graduação estagiários do Núcleo de Atenção ao Idoso da Universidade Federal de Pernambuco, além de dirigentes, técnicos e usuários dos Centros de Convivência de Idosos mantidos pela Prefeitura de Recife. Avaliou-se a experiência como capaz de integrar os conteúdos em questão, articulando os saberes de diferentes disciplinas e profissões da saúde, além de permitir o diálogo não apenas utilizando a expressão verbal, mas também corporal das concepções trazidas pelos diversos atores envolvidos. Considera-se que uma construção teórica partilhada pelo aparelho formador e pelo aparelho utilizador de profissionais de saúde foi obtida mediante a conjugação do conhecimento acumulado sobre os conteúdos e das observações resultantes do relacionamento entre aquelas instâncias. Palavras-chave: Promoção da saúde do idoso; Problematização no ensino das profissões de saúde; Teatro como estratégia pedagógica. 


\section{Abstract}

This article presents a teaching-learning experience about elderly people's health promotion in the family context, using problematization as the educational approach and employing the collective construction, discussion and presentation of a theatrical text. This experience involved the participation of researchers, technicians and students from the Elderly Healthcare Nucleus of the Federal University of Pernambuco, Brazil, as well as managers, technicians and users of the Elderly Centers supported by the municipal government of Recife. The experience was evaluated as capable of providing content integration, articulating knowledge from different health subjects and professions, besides allowing the dialogue between the concepts brought by the social actors involved, using both verbal and body language. It was considered that a theoretical construction shared by the educational system and by the public service provider was achieved through the combination between the accumulated knowledge and the observations that resulted from the relationship between them.

Keywords: Elderly Health Promotion; Problematization in Health Professions Teaching; Theater as Pedagogical Strategy.

\section{Contextualização da Experiência}

O esgotamento do modelo dominante de ensino, baseado na mera transmissão e na repetição de conhecimentos, e a inadequação do aparelho formador às novas demandas sociais vêm provocando, nas últimas décadas, uma intensa movimentação em torno da necessidade de se adotar novos paradigmas para o ensino, o que abrange a qualificação dos profissionais de saúde às profundas mudanças introduzidas pelo SUS (Cyrino e Toralles-Pereira, 2004).

A exemplo das demais instituições de ensino superior, a Universidade Federal de Pernambuco (UFPE) tem passado nos últimos anos por uma difícil, mas profícua, discussão acerca de novos conceitos de ensino entre os diferentes atores desse processo, de significativas tomadas de decisão envolvendo reformas institucionais e experimentação de novas relações e práticas no cotidiano acadêmico, do que é testemunho o implemento de reformas em vários cursos da área de saúde, algumas delas já em andamento há alguns anos, como é o caso do Curso de Medicina (Promed, 2002.

O desenvolvimento de mecanismos permanentes para a gestão compartilhada desses processos, tanto na academia quanto nas instituições de saúde, tem estreitado o convívio dos dirigentes, docentes e alunos da universidade com os gestores, gerentes e profissionais dos sistemas e dos serviços de saúde, sendo exemplos dessas iniciativas as Comissões de Integração Ensino Serviço e a implantação dos programas de qualificação das equipes de saúde da família.

Do ponto de vista pedagógico, a grande mudança verificada diz respeito à opção pelo paradigma construtivista e, entre as suas diversas correntes, pela metodologia da problematização, como proposta por Paulo Freire (1994), marcada por uma profunda visão crítica da relação entre a educação e a sociedade e pela busca das transformação dessa sociedade pela prática conscientizadora.

Esse alinhamento pedagógico se mostra bastante incisivo nos documentos norteadores das novas propostas, os quais foram aprovados em fóruns institucionais legítimos, após discussões que contaram com a participação de representantes dos vários atores sociais envolvidos. Ainda assim, a luta para superação das práticas tradicionais conservadoras tem sido ár- 
dua e a efetivação das mudanças tem se constituído numa batalha ganha palmo a palmo ou, melhor dizendo, departamento a departamento, docente a docente.

Este artigo relata uma experiência pedagógica, desenvolvida a partir de pesquisa realizada pelo Núcleo de Atenção ao Idoso (NAI), que se insere nesse contexto e que tem como objetivo contribuir para a ampliação e o fortalecimento do movimento de reforma do ensino dos profissionais de saúde, seguindo o esquema desenvolvido por Maguerez (Bordenave e Pereira, 200o). Essa experiência se constitui na construção e na encenação de um texto teatral - a partir de depoimentos relatados por idosos participantes dos grupos de convivência, bem como da observação e da teorização acerca dos problemas de inserção do idoso no grupo familiar e do levantamento de hipóteses de solução.

A escolha dessa temática se deve, em parte, ao fato de ser a promoção do envelhecimento saudável uma das linhas mestras de atuação do NAI, corporificada em pesquisas voltadas para as condições de vida e de saúde da população idosa no estado de Pernambuco e para o acompanhamento e avaliação de estratégias como grupos e centros de convivência de idosos na região metropolitana de Recife.

Outra justificativa, para a escolha do tema, foi a freqüência relacionada às condições de vida e saúde do idoso, que se mostram intimamente associadas às suas relações dentro do núcleo familiar. Ao mesmo tempo em que repousam sobre a família determinações legais e expectativas sociais, no que diz respeito ao cuidado do idoso, constata-se a emergência, neste início de terceiro milênio, de padrões econômicos e culturais no universo familiar que desafiam a efetivação desse ideal (Teixeira, 20oo; Cattani e GirardonPerlini, 2004).

Esta temática, dentro do modelo pedagógico tradicionalmente adotado pelo NAI, tem sido tratada pelos docentes, técnicos e alunos por ocasião da realização das ações individuais e coletivas cumpridas pelo idoso na unidade, a exemplo das consultas e dos grupos de auto-cuidado; da discussão de casos e apresentação de seminários; das reuniões de análises de dados coletados nas pesquisas.

O desafio enfrentado era o de ensejar a reflexão sobre temas que se fazem presentes com grande freqüência no cotidiano desses idosos. De acordo com os seus relatos, envolvendo a questão da atividade física e do envelhecimento ativo, da alimentação equilibrada, da prevenção de quedas, da proteção e inclusão social, dos cuidados com o corpo e do uso correto de medicamentos, fundamentou-se a análise. A perspectiva integradora, interdisciplinar e multiprofissional gera um aprendizado significativo para os atores sociais envolvidos na formação e na utilização de profissionais de saúde, entre os quais estão os próprios idosos na qualidade de usuários dos serviços prestados por estes profissionais.

Avaliou-se como condições positivas para o desenvolvimento da experiência o fato de que parte dos docentes já havia participado de oficinas sobre metodologias problematizadoras e tido contato com instituições de ensino que as adotam, como é o caso da Faculdade de Medicina e Enfermagem de Marília, em São Paulo.

A escolha da experiência dramatúrgica parece, plenamente, justificada, em se tratando de uma experiência que envolve a busca de superação das metodologias tradicionais de ensino superior das profissões de saúde e que lida com temáticas de promoção da saúde. Vygotsky, citado por Japiassu (1998), considera que atribuir às artes o mero papel de "adorno à vida” contradiz tudo que as pesquisas científicas na área da psicologia têm produzido ao demonstrar que elas se encontram no centro de todos os processos biológicos e sociais do indivíduo e da sociedade, mediando a relação entre o ser humano e seu mundo nos momentos mais críticos e importantes da vida.

As oportunidades perdidas de exploração de estratégias como as vivências dramatúrgicas e os jogos dramáticos no ensino e na prática da promoção de saúde podem ser exemplarmente avaliadas a partir das considerações feitas por Ruiz-Moreno e col. (2005):

Educação para a saúde envolve as práticas educativas desenvolvidas no campo da promoção da saúde, buscando atuar no âmbito coletivo sem, contudo, negar ou secundarizar a dimensão subjetiva. A articulação social-pessoal explicita-se como um desafio contemporâneo, pois os modelos notadamente prescritivos e normativos mostram-se esgotados, demandando a construção de referenciais que trabalhem com as trajetórias e itinerários dos sujeitos e de suas lutas sociais, inserindo-as na complexa sociedade contemporânea. Este eixo tem 
sido problematizado tanto no que se refere a seus aspectos conceituais (Brassolati e Andrade, 2002), como em suas proposições metodológicas (Chiesa e Westphal, 1995; Ruiz-Moreno e col., 2005, p. 16).

A presença de um integrante do grupo de docentespesquisadores com experiência de elaboração dramatúrgica e direção teatral foi também considerada elemento facilitador para a viabilização da experiência.

\section{Etapas da Metodologia Empregada}

Participaram do processo os docentes pesquisadores em saúde do idoso, do Departamento de Medicina Social (DMS) da Universidade Federal de Pernambuco (UFPE); os técnicos e alunos de graduação de diversos cursos, com prática extensionista desenvolvida no Núcleo de Atenção ao Idoso (NAI); além dos idosos cadastrados nos Grupos de Convivência vinculados ao Fundo Municipal da Assistência Social do município de Recife.

A parceria institucional foi pactuada entre a PróReitoria de Extensão da UFPE (Proext) e a Prefeitura de Recife, que se responsabilizou pela divulgação da peça, pela formação dos grupos de expectadores e pelo deslocamento deles ao Teatro Joaquim Cardoso, local da encenação, situado no espaço Cultural Benfica, pertencente a UFPE.

O texto, intitulado Do outro lado do espelho, foi elaborado a partir de uma construção coletiva, que mobilizou professores, técnicos e alunos de graduação de diversas áreas do conhecimento.

Quando se observam as propostas de Bertold Brecht e de Augusto Boal, dois teóricos que, em momentos históricos distintos contribuíram para o desenvolvimento do teatro, com esforço metodológico para superar o problema de imposição de uma "verdade" sobre o espectador, percebe-se um avanço na dramaturgia.

Brecht desejava uma platéia ativa, pensante e questionadora. No entanto, o aspecto didático de seu teatro pode facilmente induzir à suposição de uma implícita hierarquia cognitiva entre a cena e a platéia. O espectador refletiria e tomaria suas decisões baseado no que lhe é mostrado no palco. Enquanto Boal, sob direta influência da obra seminal Pedagogia do oprimido, do pedagogo Paulo Freire, ampliou a discussão brechtiana sobre a suposta passividade do es- pectador no teatro tradicional, observando-a como aliada das formas de opressão ideológica. Se Brecht instigava o seu espectador a se posicionar sobre as contradições trazidas ao palco, Boal pôs em xeque a própria essência da experiência teatral ao propor que o espectador entrasse em cena e interferisse na ação, solucionando os conflitos representados (Reis, 2007).

Partindo da teoria de Boal (2005), em que o teatro teria que ser, sobretudo, o local onde se atua, onde se ensaia a revolução, os conteúdos a serem trabalhados deveriam ser mapeados e tratados, exigindo um exercício de transdisciplinaridade, a partir de situações observadas e relatadas pelos idosos acerca do cotidiano experienciado dentro do espaço de convivência com a família. O suporte teórico foi utilizado sob um olhar crítico com a finalidade de contribuir para o levantamento de hipóteses de solução para a problemática trabalhada, o que transcorreu em oficinas de criação coletiva de texto.

Em sua formatação final, sistematizada por um grupo de redação, a peça narrou a história de Alice, uma personagem que entra em cena adotando o perfil do idoso sedentário, recluso e dependente, cuja postura vai passando por transformações gradativas no sentido de encarar a vida de forma proativa, o que não acontece sem o enfrentamento de muitas barreiras, tanto internas quanto externas.

A etapa seguinte correspondeu aos ensaios, que se duraram por dois meses. A fase das leituras e desenvolvimento do perfil dos personagens ocorreu no NAI, a partir da utilização das técnicas de:

• "construção de biografias": o grupo procurou atribuir características físicas, psicológicas e sociais às personagens e traçar sua história anterior de vida;

• "berlinda de personagens": cada “ator", com base no perfil definido na etapa anterior, respondeu às perguntas feitas pelos demais "vestindo" a personagem que se propôs a interpretar;

- "fisicalização": baseado no perfil delineado para seu personagem e nos laboratórios de observação de pessoas e situações da vida real, procurou-se expressar, pelo corpo e pela voz, as reações e os movimentos inerentes ao seu papel e aos contextos em que interage.

Até se chegar à adequação considerada aceitável pelo grupo, discussões importantes foram realizadas acerca da representação social do idoso e dos estereó- 
tipos construídos a seu respeito, eivados por vezes de preconceitos.

Por necessitar de espaço físico ampliado, a fase de preparação vocal, corporal e definição dos desenhos de cena, que corresponde à passagem das marcas ou movimentos, foi desenvolvida em salas de aula do Departamento de Medicina Social. Foram aproveitadas como oportunidades de reflexão e de aprendizado as avaliações que eram feitas ao final de cada encontro e que tiveram como eixos o papel que a atividade física desenvolvida em grupo pode aportar para o corpo e a mente de jovens e idosos, permitindo a convivência intergeracional, o lazer, a troca de conhecimentos e habilidades, a superação de certos limites biopsicossociais e a identificação e aceitação do outro mediante o exercício da alteridade.

O elenco foi constituído por 10 alunos estagiários do NAI, graduandos dos cursos de Serviço Social, Enfermagem, Fisioterapia, Psicologia, Fonoaudiologia, Nutrição, Odontologia e Terapia Ocupacional. Os cenários, os figurinos e a sonoplastia foram produzidos pela própria equipe, com a ajuda de artistas e técnicos que atuam na Prefeitura de Recife, no Núcleo de Atenção ao Idoso e na Rádio Universitária AM, onde um programa dirigido à clientela idosa é levado ao ar diariamente.

Paralelamente aos ensaios, parte do grupo de pesquisadores elaborava com os estagiários os materiais e os roteiros de discussão a serem utilizados para o trabalho em grupo com os espectadores após a encenação.

As apresentações ocorreram no Centro Cultural Benfica, espaço pertencente à UFPE, dotado de teatro, localizado em área central da cidade e com facilidade de acesso para os diversos bairros da capital e para os demais municípios da Região Metropolitana.

Após a encenação com duração média de 40 minutos, os espectadores, em torno de 45 por espetáculo, eram divididos em grupos de 8 a 10 componentes e participavam das oficinas de discussão e avaliação do texto e da encenação. Nessa ocasião, sob a preceptoria dos docentes, os alunos-atores, agora na condição de facilitadores, animavam e coordenavam a discussão acerca dos aspectos relacionados com a saúde do idoso, abordados na peça, ao mesmo tempo em que avaliavam o impacto da experiência em termos de integração entre as instituições participantes e a assimilação dos conteúdos pelos espectadores.
A avaliação da experiência foi feita com base na participação dos idosos nas oficinas temáticas, mediante ampliação e discussão crítica dos temas abordados; nas oficinas de construção do texto e de preparação da encenação; nas reuniões de acompanhamento da experiência, mantidas pelo grupo de docentes pesquisadores ao longo do processo de planejamento, preparação e realização do trabalho.

\section{Questões Trabalhadas no Texto}

O texto tem início com a apresentação dos personagens, das relações estabelecidas entre eles, do contexto socioeconômico em que se situam e do ambiente psicológico que compartilham. Alice, viúva sexagenária, vive em companhia da filha, do genro e dos netos.

Trata-se de uma família de classe média, que mora em uma cidade da região metropolitana de Recife e vive do trabalho assalariado, situando-se o casal na faixa etária dos 40 anos, com filho na idade escolar e uma filha vivendo a pós-adolescência. A cena se ambienta na sala da residência, no começo da manhã, estando todos muito agitados, aprontando-se para sair de casa e enfrentar os compromissos do dia. Alice "flutua” em meio a esse clima de intensa movimentação, em que seus problemas não são reconhecidos como prioritários pelo grupo e, dessa forma, não encontram espaço para ausculta, queixa freqüente dos idosos, configurando-se um quadro de isolamento.

A resposta do genro à pergunta que Alice ia fazer sobre os óculos que acabara de perder é emblemática: ALICE (Dirigindo-se ao genro.): Camargo, eu não sei qual é a tragédia que lhe aflige hoje, mas... Você não viu...? CAMARGO (Interrompendo.): Não, adorada sogra, não vi. E sabe por que? Porque só tenho olhos para procurar o meu barbeador que... SUMIU! Como tudo nesta casa, principalmente quando eu estou, como hoje, atrasado para chegar ao trabalho... Eureca! Como não pensei nisto antes?! O nome do culpado é Carlito! Seu querido netinho cismou de uns dias para cá, que está crescendo a barba e vive me rondando quando estou tirando a minha.

Ao mesmo tempo, os convites e sugestões feitas pelos familiares no sentido de integrá-la aos seus cotidianos não encontram ressonância. Algumas atividades, segundo ela, "não caem bem" para a sua idade, 
revelando estereótipos preconceituosos acerca do que se julgam comportamentos socialmente aceitáveis da pessoa idosa; outras atividades, porque implicam num dispêndio de energia física que o "cansaço da idade" não permite mais, justificativa que esconde, com freqüência, outros motivos, como a dificuldade de superar a inibição de trabalhar o corpo em atividades coletivas, de abandonar hábitos sedentários arraigados ou de controlar sintomas depressivos, haja visto que, na ausência de doença, a idade por si só não contraindica o exercício, pelo contrário, beneficia-se com a sua prática.

A resposta que Alice dá ao convite do neto demonstra sua postura, como se verifica no seguinte trecho de diálogo:

CARLITO: Deixa essa gente falando sozinha, vovó. Ajuda a carregar a mochila e vamos para o futsal, lá na quadra. $\mathrm{O}$ avô de Roberto não perde um treino. Coroa cabeça, o velhote. E depois, paga sorvete pra todo mundo. Dou o maior ponto.

ALICE: É isso aí, como vocês dizem. Coroa cabeça! (Com um muxoxo.) Cabeça de vento é o que ele é! O que vai fazer um velho no meio de um bando de meninos? Servir de gracejo. Só se for!

Na cena seguinte, após a saída dos familiares, Alice contempla a própria imagem refletida no espelho, figura que passa a personificar seu alter ego, com atitudes e posturas exatamente inversas às suas e que, por isso mesmo, apresenta-se como Licéia, anagrama formado com as letras do nome Alice. Na discussão que ocorre entre as duas, afloram reflexões e questionamentos acerca dos posicionamentos que ambas adotam diante das limitações e das oportunidades que a realidade proporciona.

Preconceitos em relação à expressão da sexualidade e das diferentes formas de relacionamento amoroso são revelados como formas de sublimação de desejos reprimidos. Posições refratárias em relação à participação nas atividades conjuntas ao lado dos mais jovens se apresentam como defesa prévia ante a possibilidade de rejeição.

Certamente estes comportamentos não se formam a partir do nada, representando reações a determinados padrões socioculturais que marcam o relacionamento intergeracional. Tanto Alice quanto Licéia reconhecem isso como realidade, contudo, enquanto uma delas busca se preservar, fugindo desse confronto, a outra procura lidar com ele, negociando uma ampliação de seus espaços.

ALICE: Acho até blasfêmia ficar reclamando da vida que levo. Há tanta velhice desamparada por aí, sem um teto para descansar os ossos, sem a comidinha na hora certa, sem um pé de família que venha trazer um comprimido para aliviar uma dor!

LICÉIA: É claro que há, mas há também outro envelhecer, que troca a cadeira de balanço pela atividade física.

ALICE (Irônica, imitando o gestual da caminhada, da natação, da ginástica.): Opa! Vou começar a achar que devia ter aceitado o convite de Camargo para ir ao Clube. ( $E$ voltando à rabugice.) 0 que é que eu perdi no Clube, menina?

LICÉIA: Nada! Por isso mesmo devia ir lá conferir o que tinha a ganhar.

ALICE: Eu já sei o que ia ganhar fazendo exercício: mexer com as minhas palpitações e com o meu reumatismo que estão calminhos, aqui, sem me incomodar há uns dois meses.

LICÉIA: Tudo isso é ferrugem, Alice! É o corpo pedindo para ser despertado! Vai ativar esta circulação, aquecer estes músculos, desintoxicar destes remédios...

ALICE (Com uma crescente revolta, aumentando progressivamente o tom de voz.): Ah, sim! Vai, Alice, caminhar! Vai, Alice, nadar! Vai, Alice, fazer isso! Vai, Alice, fazer aquilo! Vai, Alice, namorar... (Para, de repente, como se houvesse falado demais.).

LICÉIA: (Que acompanhou animada o desabafo, batendo palmas ao final.): E por que não? Pode acontecer, também. Você ainda está viva, não está? O coração pode, de repente, palpitar daquele outro jeito.

A chegada de Francineide, a empregada, provoca em Alice um grande esforço no sentido de recalcar seu outro "eu", o que ela faz tentando, sem sucesso, ocultar Licéia outra vez no fundo do espelho. Embora sua atitude diante da empregada, a princípio, demonstre informalidade, exigência e distanciamento, Francineide, ora apelando para a dissimulação ora usando de irreverência, neutraliza o tom autoritário das cobranças e das ordens que recebe:

FRANCINEIDE (Entrando, enquanto boceja.): Bom dia, Dona Alice. 
ALICE : Quase que era boa noite, Francineide. Qual é a desculpa de hoje? Outro dia, morreu o tio; a semana passada, foi a sogra; ainda sobrou alguém na sua família?

FRANCINEIDE: 0 pior é que a senhora tem razão. Tá se acabando é todo mundo. O que eu tenho ido naquele cemitério, não é brincadeira, viu!

Além disso, Francineide acaba percebendo a presença de outra Alice, com posições mais liberais e ousadas e, espertamente, vai procurando fortalecê-la. Parece ficar claro que no espaço doméstico, a idosa também não consegue mais ocupar o papel de administradora do lar, já que não é vista como a patroa. A casa, ainda que possa ser de sua propriedade, termina por obedecer ao comando de seus familiares mais jovens e que, na verdade, são seus agregados.

LICÉIA (Impedindo que ela saia.): Vamos com calma, Francineide. Não lhe passou pela cabeça que podemos ser irmãs gêmeas? Afinal, somos tão parecidas, assim? Eu me acho muito mais light?

FRANCINEIDE (Examinando bem as duas.): Que são muito parecidas, são, agora que a senhora pega mais leve do que essa outra aí, isso pega. (Estende a mão e cumprimenta Licéia.) Muito prazer, Dona...

LICÉIA: Pode me chamar de Licéia.

FRANCINEIDE: Licéia? Saquei! Licéia é Alice ao contrário! A sua mãe devia gostar de trocadilhos e charadas, não? Eu, modéstia a parte, acerto todas que o Olavo Olívio conta...

LICÉIA: Olavo Olívio?

ALICE (Expressando desaprovação.): É um programa de rádio que ela escuta toda manhã.

FRANCINEIDE: Dona Licéia, vá desculpando qualquer coisa... agora, me deixa ir...

ALICE (Autoritária, com o dedo em riste.): ... cuidar do almoço!

FRANCINEIDE (Aborrecida.): Eu não estou dizendo? Dona Alice, a senhora me dá só o tempo de tomar dois sonrisal e uma neosaldina? (Sai, resmungando, com as mãos na testa, queixosa.)

Neste seguimento do texto, que se passa na cozinha da residência, os personagens, após um debate acalorado, no qual ficam claro seus pontos de vista sobre a qualidade do serviço doméstico, apresentam algumas noções básicas sobre a alimentação saudável, cantando e dançando em uníssono um chorinho cujo refrão reproduzimos aqui.

Chega de arenga, confusão e alvoroço

Quero saber o que é que temos pro almoço.

Feijão com arroz é o que se come todo dia

Ou sai algo diferente pra quebrar a monotonia?

A conversa, na cena seguinte, aborda a falta de espaço do idoso para fazer valer suas preferências, aqui exemplificada pelo gosto musical. A cultura dos grupos etários mais jovens se faz dominante e a falta de respeito desses grupos pelas preferências do idoso acaba reduzindo suas possibilidades de desfrutar dos produtos e situações com os quais se identifica. Sua posição passiva e conformista, abrindo mão de suas preferências, certamente agrava a condição, contribuindo para sua alienação dentro dos grupos transgeracionais que integra, a começar pela família:

LICÉIA: Vamos escolher um bom disco de bolero?

ALICE (Com um suspiro de desânimo diante da insistência da outra.): Aqui não tem disco de bolero. Ninguém escuta mais isso.

LICÉIA: E por que não?

ALICE: Haja paciência! Porque eles não gostam!

LICÉIA: Eles?! E você? Gostava tanto, dançava tão bem...

FRANCINEIDE: Isso, dona Licéia! Entrega ela!

ALICE (Melancólica.): Isso era no tempo em que o meu Luís ainda estava comigo...

LICÉIA : Você deu fim aos discos?

ALICE : Não, mas vou fazer isso qualquer hora. Estão guardados lá no meu quarto. Acontece que é tudo vinil e hoje só existe aparelho de CD.

Na próxima seqüência, aparece de maneira muito explícita a possibilidade de expressão pelo idoso dos seus conhecimentos, experiências e habilidades, que passam a ser intercambiados com as demais gerações. Além disso, nesse caso específico, por tratar-se da dança, proporciona lazer, auto e heterocontato corporal, exercício físico, oportunidade de beneficiar o corpo e a mente com a prática do equilíbrio e do ritmo, além de promover o alívio de tensões e a convivialidade. É necessário acentuar que o desfecho da situação vivida pelos personagens - a queda durante o apren- 
dizado da dança - é aproveitado para transmitir a importância da redução de riscos de acidentes no ambiente doméstico, mas de uma forma não radical, evitando reforçar o sedentarismo como medida preventiva. Isso é acentuado pelo fato de que os personagens transmitem as recomendações para um ambiente seguro, movimentando-se o grupo de atores ao som deste rap:

Desafogar o espaço, melhorar a circulação

Para evitar tropeços? Boa iluminação

Cuidado nesse piso que eu não posso escorregar

Suporte no banheiro pra você se apoiar

Escolha um sapato que não te faça cair

Se sofre de tonturas procure se prevenir

Escada bem segura pra subir e pra descer

Agindo assim as quedas nunca vão acontecer

Enquanto os personagens centrais saem de cena, por um instante, o "interlúdio" é proporcionado pelo programa de rádio que Francineide escuta todos os dias, pelo qual noções básicas acerca dos cuidados com o corpo, com a automedicação e com a polifarmácia são tratados pelo apresentador, Olavo Olívio, numa linguagem simples e bem-humorada:

"A casa a que eu me refiro, gente amiga, é o nosso corpo. Essa é a única casa que, de fato, énossa. Eo que estamos fazendo para conservá-la? Expondo nossa pele ao sol causticante do meio-dia sem os devidos cuidados. Pô! Usa um chapeuzinho, uma sombrinha. Se vai à praia, mete um filtro solar $e$ evita ficar quarando o dia inteiro. $\varepsilon$ em casa, depois do banho? Está usando um hidratante? Já percebeu que a pele vai ressecando e perdendo a elasticidade com a idade? Não vem com desculpa de que hidratante é produto caro que essa não cola. $\varepsilon$ esse calcanhar rachando? Você nem está aí, não é? Vai deixar inflamar bem, inchar, infeccionar, virar aquela meleca, ganhar o apelido de "pé-de-bombo" para se cuidar. Tenha paciência! Hidrata, passa um oleozinho de amêndoa, lubrifica esses calcanhares, cara! Conhece aquele ditado: "Sebo nas canelas"? É isso aí! E outra coisa:vamos aproveitar a hora do banho pra fazer uma revisão na lataria, gente! $\varepsilon$ a melhor hora pra ver se tem uma mancha aqui, um arranhado ali, um catombo acolá."

A questão se volta, neste trecho, para a autonomia, atributo que mesmo o idoso são, por uma questão de hábito, cultura ou acomodação, não exerce, preferindo que outras pessoas resolvam assuntos de seu interesse assumindo, de certa forma, a condição de incapaz. LICÉIA (Vendo o ar de frustração de Alice.): 0 que foi, agora? Estava tão bem, há pouco. Por que essa cara de “meu mundo caiu”? A Suzana não pode levá-la ao médico?

ALICE: Nem ao médico, nem ao banco! Que droga é ser dependente dos outros!

LICÉIA: Ora, Dona Alice, faça-me o favor! Você não é inválida, criatura! Vá resolver suas coisas e deixe de esperar pelos outros! Qual é o mistério de se ir ao médico e ao banco?

ALICE: Mistério nenhum, quando se conta com alguém para levar e trazer. Não tenho mais idade para sair sozinha.

LICÉIA: Isso é necessário para os idosos que não têm condições de ir para a rua sem correr riscos. Mas, você...?! Enxerga, ouve, anda, tem boa cabeça graças a Deus... Qual é o problema? Deixe de choramingar e vamos à luta.

Tomar o transporte sozinha, ir ao médico, usar o banco são situações exemplificadas no texto que, paralelamente, abordam a necessidade de que o idoso conheça e exerça seus direitos, aqui representados pela gratuidade do transporte e pela prioridade nas filas.

LICÉIA: Lembrou de trazer a carteirinha?

ALICE: Carteirinha? Que carteirinha?

LICÉIA: A carteirinha que permite aos idosos subir pela porta dianteira, é claro!

ALICE: E você acha que eu tenho cara de estar pedindo arrego para viajar?

LICÉIA: Arrego coisa nenhuma, minha cara, é um direito que foi assegurado ao idoso.

ALICE: Eu nunca me interessei em tirar essa carteira. Nem me lembro do tempo que andei de ônibus.

LICÉIA: Pois devia se interessar, sim. É uma maneira de se tornar independente e economizar uma grana.

E, mais adiante, quando as personagens já estão no banco:

ALICE (Colocando-se no final da fila.): Se esta fila não andar depressa, vamos perder o horário do médico.

LICÉIA: Mas você não precisa ficar aqui. Como idosa, tem atendimento preferencial. 
ALICE : Ah, essa não! Não vou passar na frente dos outros para ficar escutando gracinhas. E você mesma disse que eu não sou uma inválida...

LICÉIA: Sim, mas não pode ficar tanto tempo em pé, numa fila, como os clientes mais jovens. Pensando nisso é que fizeram a lei. Vou falar com o gerente. (Dirige-se até o gerente.) Bom dia, senhor. Tenho uma reclamação.

GERENTE: Bom dia, senhora. O que houve?

LICÉIA: O que houve é que esta agência está descumprindo a lei!

GERENTE (Preocupado,): Descumprindo a lei? Como assim?

LICÉIA: Não está disponibilizando um caixa exclusivo para idosos, gestantes, deficientes físicos.

GERENTE: É que hoje tivemos a falta de vários funcionários. Essa história da dengue, a senhora sabe. É por isso que estamos funcionando com fila única. De qualquer jeito, não há prejuízo para vocês porque os caixas estão instruídos para dar prioridade aos idosos, gestantes...

LICÉIA: Tudo bem, mas o senhor há de concordar comigo que isto cria uma situação constrangedora para o idoso e para os outros clientes que estão na fila.

GERENTE: É verdade, mas isso se justificava se fosse um dia de pagamento do INSS, por exemplo. Hoje não tenho razão para isso, deixar um caixa "empatado" atendendo de hora em hora um idoso ou uma gestante que chega.

LICÉIA: Mas o senhor pode colocar um aviso em um dos caixas informando que ele atende preferencialmente idosos, gestantes, pessoas com crianças ao colo, deficientes físicos. Certo?

GERENTE (Com um suspiro.): Certo, senhora, vou providenciar. Mais algum problema?

LICÉIA: Não, senhor. Obrigado e tenha um bom-dia.

Nestas últimas cenas, Licéia desaparece, simbolizando a incorporação, por Alice, daquele "eu" que ela tanto sufoca e que aos poucos vai deixando aflorar. $\mathrm{O}$ teste final é representado pelo contato com a vida fora dos limites do domicílio, enfrentando sozinha situações que, provavelmente, não haverão mais de amedrontá-la ou de exigir a ajuda de outrem, como é o caso das cenas que vivencia nesta saída de casa, incluindo a aproximação com alguém que se dispõe a cortejá-la. Daí para a entrada em um grupo de convivência parece ter sido uma questão de tempo. Aliás, de pouco tempo, o que prenuncia o início de um novo padrão de relacionamento com a família e com o mundo, como deixa antever a última fala da peça:

ALICE (Chegando ao portão de uma casa com uma placa indicando ser um Grupo de Convivência e dirigindose à platéia.): Bem, a partir desse dia, quando encaro Licéia no espelho, percebo que somos a mesma e única pessoa, com angústias e medos, mas também com esperança e vontade de viver a vida. Quanto ao Cícero, ele se tornou um bom amigo, sempre com aquelas brincadeirinhas sem graça, mas temos nos divertido juntos e... quem sabe, algum dia eu lhe dê mais um pouquinho de confiança. Foi ele quem me disse para procurar este grupo de convivência. Até marcou encontro comigo, aqui, mas pontualidade não é o seu forte. Minha família também ficou de aparecer para me dar uma força, mas aqueles ali..

(Neste momento, entram em cena Cícero, Camargo, Suzana, Paloma, Carlito e Francineide. Cumprimentam a platéia. Termina a encenação.)

\section{Avaliação da Experiência}

Foi considerada positiva a escolha de uma idosa saudável como personagem central, favorecendo, dessa forma, a "desconstrução" do envelhecer como sinônimo de adoecer, firmando a concepção atual de que um idoso pode ser considerado saudável mesmo na ocorrência de enfermidades, desde que as elas estejam sob controle e que a sua capacidade funcional esteja preservada (WHO, 2005; Ramos, 2002).

Ficou claro que é no momento em que as funções começam a se deteriorar os problemas começam a surgir, evidenciando que o conceito de saúde está, como afirma Kalache (1996), intimamente ligado à manutenção da autonomia, entendida como exercício do autogoverno, capacidade de decisão sobre sua própria vida.

Um tema recorrente, durante a avaliação da experiência, foi a importância atribuída, pelos próprios idosos, às ações de promoção da saúde, entendendo-se que as ações de assistência à saúde serão incapazes de responder às demandas representadas pelo rápido 
processo de envelhecimento da população, posição sustentada por vários autores que apontam a necessidade de que seja conferida prioridade à temática do envelhecimento e à emergência na execução de ações e estratégias que promovam o envelhecimento ativo e bem-sucedido (Veras,1994; Silvestre e col., 1996; Chaimowicz, 1998).

Foi destacado, pelos diferentes atores participantes da experiência, que a ampliação das práticas de promoção da saúde voltadas para a promoção do envelhecimento ativo, caracterizado pela experiência positiva de longevidade com preservação de capacidades e do potencial de desenvolvimento do indivíduo, em que as condições de vida satisfatórias e a existência de políticas sociais voltadas ao segmento idoso são essenciais (WHO/NMH/NPH, 2002), implica na necessidade de políticas públicas e da participação social no processo de sua conquista (Buss, 2003; Rootman, 2001).

A participação de idosos dos grupos de convivência vinculados ao Fundo Municipal da Assistência Social do município de Recife foi essencial para a elaboração dos personagens, bem como para sua atuação nos grupos de discussão após a encenação. Isso demonstrou a compreensão do conteúdo veiculado e a posição crítica a respeito do tema, aprovando ou discordando de determinadas posturas assumidas pelos personagens e trazendo suas justificativas para o debate. Mesmo assim, as discussões convergiram muito mais para as questões relacionadas às possibilidades de fortalecimento das ações de promoção da saúde, com destaque para a necessidade de inclusão das famílias, do que para a constatação dos problemas tratados ou para as recomendações técnicas propostas.

Do ponto de vista pedagógico, os alunos que participaram da vivência referiram terem tido a oportunidade de realizar um trabalho interdisciplinar, construindo uma teorização a partir de suas observações, discussões e pesquisas, organizando esses conteúdos para gerar os produtos propostos, a saber, o texto escrito e a sua representação. Destacaram como ponto alto da experiência a oportunidade de trabalhar com colegas de outras áreas do conhecimento, o que entenderam como contribuição importante para a formação de recursos humanos no trabalho de promoção da saúde do idoso. Frisaram ainda a desproporção entre as prescrições teóricas e as oportunidades de vivência concreta de incorporação, no trabalho em saúde, de saberes distintos, incluindo aqueles provenientes da diversidade profissional dos atores, das relações interpessoais que se desenvolvem entre eles e com os usuários, bem como, no caso específico das ações de promoção da saúde, da heterogeneidade dos espaços de realização do trabalho, exigindo estratégias alternativas de organização e funcionamento dinâmica das atividades.

A metodologia escolhida, portanto, destaca a valorização do idoso, permeando o conhecimento sobre o processo do envelhecimento e a repercussão nas instâncias políticas, econômicas e sociais, que, efetivamente, irão contribuir para o bem-estar biopsicossocial do indivíduo com idade mais avançada, favorecendo sua qualidade de vida. Destacamos a importância da participação do discente na construção do seu conhecimento por meio dessa problematização nos temas vivenciados e reportados pelos idosos, foco da pesquisa.

Avaliou-se, ainda, que os docentes conseguiram conduzir o trabalho dentro da metodologia problematizadora, embora tenham revelado o esforço que precisaram desenvolver em alguns momentos da experiência para não ceder à tentação de atropelar o processo de teorização fornecendo a "solução" já consagrada pelo seu acúmulo pessoal de conhecimento ou de coordenar de forma excessivamente diretiva as atividades prejudicando a livre expressão dos integrantes e o desenvolvimento de mecanismos de autogestão no grupo.

O trabalho extrapolou o calendário previsto requerendo um tempo, desde o planejamento até a execução, que ultrapassou em duas semanas um semestre letivo. Excedeu também a carga horária semanal prevista, principalmente na fase final dos ensaios.

Por fim, os participantes da experiência consideraram que todo o ciclo se constituiu numa experiência válida de aprendizagem envolvendo diferentes atores, requerendo a contribuição de cada um e recebendo a marca de todos.

\section{Referências}

\author{
BOAL, A. Teatro do oprimido e outras poéticas \\ políticas. Rio de Janeiro: Civilização Brasileira, 2005.
}


BORDENAVE, J. D.; PEREIRA, A. M. (Org.). O que é ensinar. In:____._Estratégias de ensino-

aprendizagem. Petrópolis: Vozes, 200o. p. 39-57

BUSS, P. M. M. Uma introdução ao conceito de promoção da saúde. In: CZERESNIA, C.; FREITAS, C. M. (Org.). Promoção da saúde: conceitos, reflexões, tendências. Rio de Janeiro: Fiocruz, 2003. p. 15-38.

CATTANI, R. B.; GIRARDON-PERLINI, N. M. O. Cuidar do idoso doente no domicílio na voz de cuidadores familiares. Revista Eletrônica de Enfermagem, v. 6, n. 2, p. 254-71, 2004. Disponível em: <http:// www.fen.ufg.br >. Acesso em: 15 jan 2007.

CHAIMOWICZ, F. Os idosos brasileiros no século XXI: demografia, saúde e sociedade. Belo Horizonte: Postgraduate, 1998.

CYRINO, E. G.; TORALLES-PEREIRA, M. L. Trabalhando com estratégias de ensinoaprendizagem por descoberta na área de saúde: a problematização e a aprendizagem baseada em problemas. Cadernos de Saúde Pública, Rio de Janeiro, v. 20, n. 3, p. 782, maio/jun. 2004.

FREIRE, P. Pedagogia do oprimido. 22. ed. São Paulo: Paz e Terra, 1994.

JAPIASSU, R. O. V. Jogos teatrais na escola pública. Rev. Fac. Educ., São Paulo, v. 24, n. 2, p. 82, jul./ dez.. 1998.

KALACHE, A. Envelhecimento no contexto internacional: a perspectiva da Organização Mundial da Saúde. In: SEMINÁRIO INTERNACIONAL SOBRE ENVELHECIMENTO POPULACIONAL: UMAAGENDA PARA O FINAL DO SÉCULO, 1996, Brasília. Anais... Brasília, DF: Ministério da Previdência e Assistência Social, 1996. p. 13-15.

Recebido em: 29/0I/2007

Aprovado em: 01/08/2007
PROMED - PROGRAMA DE INCENTIVO A MUDANÇAS CURRICULARES NOS CURSOS DE MEDICINA. Relatório das oficinas regionais: maio e junho de 2002. Brasília, DF: Secretaria de Políticas de Saúde, 2002.

RAMOS, M. P. Apoio social e saúde entre idosos. Sociologias, Porto Alegre, v. 4, n. 7, p. 156-175, 2002.

REIS, L. A. Piscator, Brecht, Boal e Artaud: considerações sobre o teatro político. Disponível em: <www.ccba.com.br/dados/anexos/luis_reis.doc>. Acesso em: 2 ago. 2007.

ROOTMAN, I. A framework for health promotion evaluation. In: ROOTMAN, I. (Org.). Evaluation in health promotion: principles and perspectives. Copenhague: WHO Regional Publications, 2001, p. 7-38.

RUIZ-MORENO, L. et al. Jornal vivo: relato de uma experiência de ensino-aprendizagem na área da saúde. Interface, Botucatu, v. 9, n. 16, set. 2004/ fev. 2005 .

SILVESTRE, J. A. et al. O envelhecimento populacional brasileiro e o setor saúde. Arquivos de Geriatria e Gerontologia, São Paulo, v. x, n. 1, p. 81-89, set. 1996.

TEIXEIRA, F. O idoso e a família: os dois lados da mesma moeda. Disponível em: <http://www.partes. com.br/terceira_idadeo8.html $>$. Acesso em: $15 \mathrm{jan}$. 2007.

VERAS, R. P. País jovem com cabelos brancos: a saúde do idoso no Brasil. 3. ed. Rio de Janeiro: Relume Dumará: UERJ, 1994.

WHO. Envelhecimento ativo: uma política de saúde. Brasília, DF: Organização Pan-Americana da Saúde, 2005 .

WHO. Active ageing: a policy framework. Geneva, 2002. Disponível em: <http://www.whqlibdoc. who.int/hq/2002/WHO_NMH_NPH_02.8.pdf >. Acesso em: 13 nov. 2006. 